\title{
Announcements
}

\section{Curt P. Richter Prize in Psychoneuroendocrinology}

Through the generosity of the Irish Foundation for Human Development, an Annual Prize has been established for meritorious research in the area of Psychoneuroendocrinology. The sum of $\$ 1,000$ will be awarded annually for the best essay or manuscript (original research or a review article including research) submitted by a scientist or physician under 35 years of age. The winning paper will be published in the journal, Psychoneuroendocrinology. The aim of the prize is to encourage younger scientists to contribute to this interdisciplinary field.

Manuscripts should be submitted in triplicate to: Dr. Fleur L Strand, Secretary, International Society of Psychoneuroendocrinology, Biology Department, New York University, Washington Square, New York, NY 10003, USA

All submissions will be screened by a broad committee of established psychoneuroendocrinologists. Deadline April 1, 1980

\section{IUPS Satellite Symposium on Gondal Steroids and Brain Function}

Berlin (West), July 10-11, 1980

The main lectures, given by invited speakers, will be complemented by a limited number of poster presentations.

This symposium is sponsored by the International Society for Neuroendocrinology. There will be no registrations fee. 


\section{3th Annual Meeting of the Society for the Study of Reproduction}

Ann Arbor, August 12-14, 1980

The program includes sessions devoted to research papers, and a symposium on 'Endocrine Signaling in Reproduction'. For additional information about the symposium or the submission of contributed papers, please contact: Business Manager, The Society for the Study of Reproduction, 113 North Nell Street, Champaign, ILL 61820, USA

\section{VIIlth International Symposium on Neurosecretion}

The VIIIth International Symposium on Neurosecretion, the first to be held in North America, will be convened at the Friday Harbor Laboratories of the University of Washington on San Juan Island on September 4-10, 1980. Available living facilities will restrict the number of participants to approximately 90 who will be selected by the Organizing Committee. A preliminary program and description will be available in November. Inquiries and applications should be addressed to the Chairman of the Organizing Committee, Professor Donald S. Farner, Department of Zoology, University of Washington, Seattle, WA 98195, USA 